\title{
Determination of the activity of selected antioxidant enzymes during bovine laminitis, induced by oligofructose overload"1)
}

\author{
MUHAMMAD ABID HAYAT, JIAFENG DING, YUEPENG LI, XIANHAO ZHANG, \\ JIANTAO ZHANG, SHUAICHEN LI, HONG BIN WANG
}

Department of Veterinary Surgery, College of Veterinary Medicine, Northeast Agricultural University, Harbin 150030, P. R. China and Heilongjiang Key Laboratory for Laboratory Animals and Comparative Medicine, Harbin 150030, P. R. China

Hayat M. A., Ding J., Li Y., Zhang X., Zhang J., Li S., Wang H. B.

Determination of the activity of selected antioxidant enzymes during bovine laminitis, induced by oligofructose overload

\section{Summary}

Alimentary oligofructose (OF) overload induces acute laminitis in dairy heifers. We examined the correlation between acute bovine laminitis and antioxidant levels by measuring the activities of malondialdehyde (MDA), catalase (CAT), reduced glutathione (GSH), and superoxide dismutase (SOD) in dairy heifers with acute bovine laminitis. A total of 12 clinically healthy non-pregnant Chinese Holstein heifers, aged between 18-26 months $(20.67 \pm 3.01 \mathrm{mo})$, weighing $335-403 \mathrm{~kg}(379.71 \pm 19.87 \mathrm{~kg})$, and with $\mathrm{BCS}$ ranging from 2.7 to 3.3 were selected and divided into two groups of six animals: an OF-treated group and a control group. The OF-treated heifers $(\mathrm{n}=6)$ received $17 \mathrm{~g} / \mathrm{kg} \mathrm{BW}$ of oligofructose dissolved in $2 \mathrm{~L} / 100 \mathrm{~kg} \mathrm{BW}$ of tap water, whereas the control heifers $(n=6)$ received $2 \mathrm{~L} / 100 \mathrm{~kg} \mathrm{BW}$ of tap water. Blood samples of OF-treated and the control heifers were collected at $-72 \mathrm{~h}$ before, as well as $0,6,12,18,24,36,48,60$ and $72 \mathrm{~h}$ after $\mathrm{OF}$ overload. Malondialdehyde (MDA), superoxide dismutase (SOD), reduced glutathione (GSH), and catalase (CAT) activity levels were measured by authenticated standard methods using blood samples. The mean concentration of superoxide dismutase (SOD) was significantly lower $(\mathrm{p}<0.01)$ in the OF-treated heifers from $24 \mathrm{~h}$ to $72 \mathrm{~h}$ and significantly lower $(\mathrm{p}<0.05)$ at $18 \mathrm{~h}$ compared to the control group. Malondialdehyde (MDA) level was significantly higher $(p<0.01)$ at $24 \mathrm{~h}$ to $72 \mathrm{~h}$ and significant increased $(\mathrm{p}<0.05)$ at $12 \mathrm{~h}$ to $18 \mathrm{~h}$ in $\mathrm{OF}$-treated heifers compared with healthy heifers. There were no significant differences in GSH and CAT activities between the control and treatment groups. Our study showed that inadequate levels of antioxidants (enzymatic and non-enzymatic) may be linked to oxidative stress in sick heifers. OF-treated heifers had decreased SOD and increased MDA in response to acute laminitis. Therefore, SOD, GSH, CAT, and MDA activities may play a dynamic role in the etiopathogenesis of acute laminitis in dairy heifers. However, further detailed research is required to describe these responses and to develop strategies to control acute laminitis.

Keywords: acute bovine laminitis, oligofructose, superoxide dismutase, malondialdehyde, reduced glutathione, catalase

Acute bovine laminitis is a systemic disease with confined manifestations that affect the claws. It can cause serious economic losses to the dairy industry because cows with laminitis have reduced reproductive performance, decreased milk yield, high culling rates, and increased cost of veterinary intervention $(6,13)$. Equine laminitis is well-characterized, but the pathogenesis of acute bovine laminitis remains unclear. Recent studies have found that alimentary

1) The present study was funded by the National Key R \& D Program of China (Project No. 2017YFD0502200) and Heilongjiang Provincial Funding for National Subjects (GX18B023). oligo-fructose (OF) induces acute bovine laminitis, leading to histological changes in the dermo-epidermal junction of the claws $(6,38)$.

Oxidative stress is defined as a change in the balance of cellular oxidation-reduction reactions, where there is an reactive oxygen species (ROS) are released excessively, and their removoal is reduced due to inadequate antioxidant enzyme activity (22).

Increased activity of antioxidants may prevent cell damage caused by metabolic disorders $(9,41$, 42). Laminitis is known to induce oxidative stress $(28,32)$, where under these oxidative conditions, 
increased ROS causes hoof tissue dyskeratosis (40), cartilage degeneration, and chondrocyte apoptosis (17). Organisms have developed numerous defense mechanisms to prevent damage of the cellular structure caused by free radicals through the antioxidant defense systems (29).

Antioxidants are molecules that prevent or reduce free radical reactions to delay or prevent cellular damage (45). Antioxidants preserve cells from the harmful effects of free radicals. Free radicals are molecules that have an unshared electron that is particularly active, and this electron can react rapidly with oxygen to form ROS. The body produces ROS endogenously as a result of normal cell activity, or as a response to exposure to free redicals in polluted air, cigarette smoke and ultavoilet radiations (UV) in sun rays. Cells control ROS levels through the antioxidative defense systems, while ROS activates antioxidant signaling between cells, leading to an increased antioxidative capacity, a process called oxidative stress (43).

Components of reactive oxygen species (ROS) are produced during physiological and metabolic functions causing harmful oxidative reactions under conditions of excessive production. Superoxide dismutase (SOD) is the first line of defense against ROS and is active in the detoxification of superoxide radicals $(3,11)$. Reduced glutathione (GSH) is the most important cellular antioxidant, which plays a major role in protecting cells against oxidative stress caused by $\operatorname{ROS}(1,3,34)$. Under normal conditions, catalase (CAT) is of no great importance to most cell types, but in the presence of oxidative stress it is the most adaptive antioxidant enzyme and plays a important role in cell defense against oxidative damage (14). Polyunsaturated fatty acids (PUFAs) in cell membranes are the primary targets of ROS. The resulting lipid peroxidation may cause damage of the cell structure and functions $(15,44)$. In addition, the decompositions of lipid hydroperoxides produces a wide variety of end-products, including malondialdehyde (MDA). One of the most frequently used ROS biomarkers, providing an indication of lipid peroxidation intensity, is MDA, which is a byproduct of lipid peroxidation $(8,10,15,30)$. The thiobarbituric acid (TBA) assay is the most common and easiest method used as an indicator of lipid peroxidation and free radical activity in biological samples. The assay

Tab. 1. Locomotion scoring system

\begin{tabular}{|c|c|c|}
\hline Score & Description & Assessment criteria \\
\hline 1 & Normal & The heifer stands and walk with level-back posture. Its gait is normal. \\
\hline 2 & Mildly lame & $\begin{array}{l}\text { The heifer stands with level-back posture while walking develops an } \\
\text { arched back-posture. Its gait remains normal. }\end{array}$ \\
\hline 3 & Moderately lame & $\begin{array}{l}\text { An arched-back posture is evident both while standing and walking. The } \\
\text { heifer's gait is best described as short striding with } 1 \text { or more limbs/feet. }\end{array}$ \\
\hline 4 & Lame & $\begin{array}{l}\text { An arched-back posture is always evident and gait is best decribed as } \\
1 \text { deliberate step at a time. The heifer favors } 1 \text { or more limbs/feet. }\end{array}$ \\
\hline 5 & Severely lame & $\begin{array}{l}\text { The heifer additionally shows an inability or extreme reluctance to bear } \\
\text { weight on } 1 \text { or more of its limbs/feet. }\end{array}$ \\
\hline
\end{tabular}

is based on the reaction of two molecules of TBA with one of MDA $(3,30)$.

Changes in the activity of SOD, CAT, GSH, and MDA have not been reported in laminitis-induced dairy heifers. Therefore, we examined the level of oxidative stress and activities antioxidant enzymes during the first $72 \mathrm{~h}$ of animals developing induced acute bovine laminitis through OF overload. We hypothesized that oxidative stress caused by acute laminitis changes antioxidant enzyme activity levels in dairy heifers.

\section{Material and methods}

Animals. Twelve clinically healthy non-pregnant Chinese Holstein heifers with normal locomotion, without a history of serious claw lesions, aged between 18 to 26 months (20.67 $\pm 3.01 \mathrm{mo})$, weighing 335 to $403 \mathrm{~kg}$ (379.71 $\pm 19.87 \mathrm{~kg}$ ), and with BCS ranging from 2.7 to 3.3 were selected. Before the commencement of the experiment, Heifers were acclimated for 30 days to assure free access to feed grass hay and adequate drinking water. Three days before the experiment, the jugular vein was catheterized.

Experimental design and treatments. Twelve heifers were allocated into two groups of six individuals: an OF-treated group and a control group. According to (6) the OF-treated heifers $(\mathrm{n}=6)$ received $17 \mathrm{~g} / \mathrm{kg} \mathrm{BW}$ of oligofructose (Bailong Bio-Tech Company, Jinan, China) dissolved in $2 \mathrm{~L} / 100 \mathrm{~kg} \mathrm{BW}$ of tap water, whereas the control heifers $(\mathrm{n}=6)$ received $2 \mathrm{~L} / 100 \mathrm{~kg} \mathrm{BW}$ of tap water at $0 \mathrm{~h}$. Three days $(-72 \mathrm{~h}$ ) before the high oral dose of oligofructose, a $5 \%$ dose of oligofructose was administered daily. During the pre-experimental period, heifers were trained to have their front feet lifted and examined, and to be directed by hand to walk and trot. During the experiment, all heifers were housed in a tie-stall on a concrete floor bedded with wood flakes to a depth of 2-4 cm and were fed grass hay ad libitum. After 72 hours of OF-overload, heifers were euthanized.

For animal welfare, supportive therapy was given as Ringer lactate (Peace Veterinary Medicine, Harbin China; $15 \mathrm{ml} / \mathrm{kg} \mathrm{BW}$ ) and sodium bicarbonate (Peace Veterinary Medicine, Harbin China; $84 \mathrm{~g} / \mathrm{L} ; 1.5 \mathrm{~mL} / \mathrm{kg}$ of BW) at 18 and $24 \mathrm{~h}$ after oligofructose overload and calcium borogluconate (Peace Veterinary Medicine, Harbin China; $14 \mathrm{mg}$ of $\mathrm{Ca} / \mathrm{mL} ; 1.4 \mathrm{~mL} / \mathrm{kg}$ of BW) at $18 \mathrm{~h}$.

The experiment was carried out following the animal ethical standards (animal ethics approval SRM-13) established by the College of Veterinary Medicine, Northeast Agricultural University in Harbin, Republic of China.

Locomotion scoring and histopathological examination. Locomotion scoring was assessed according to the method described by (39) as shown in Tab. 1. Histopathological examination of claw was carried out according to (7). The purpose of the locomotion scoring and histopathological examination were to provide unbiased confirmation or disproof of the development of the laminitis after OF overload.

Blood sampling. From selected control and OF-treated heifers, $5 \mathrm{ml}$ blood 
samples were collected from jugular vein by puncture. Blood samples were centrifuged at $5000 \mathrm{r} / \mathrm{min}$ for $10 \mathrm{~min}-$ utes to separate serum from plasma. The separated serums were used to determine the activity levels of superoxide dismutase (SOD), reduced glutathione (GSH), catalase (CAT) levels, and malondialdehyde (MDA).

Determination of SOD activity. SOD detection Microplate test Kit (cat no. A001-3 WST-1) from Nanjing Jiancheng Bioengineering Institute (Nanjing, People's Republic of China) was used to evaluate total SOD activity. The assay was performed following the manufacturer's instructions. SOD increases the dismutation of toxic superoxides that are generated by ROS to oxygen and hydrogen peroxide. To measure SOD activity, xanthine oxidase (XOD) and xanthine were combined to produce superoxide radicals that were mixed with water-soluble tetrazolium-1 (WST-1) to form a red water-soluble tetrazolium-1 formazan dye. SOD activity was measured by the degree of inhibition during this reaction. One unit of SOD activity was defined as 50 percent inhibition of WST- 1 rate under assay conditions. A standard curve of SOD activity was generated $450 \mathrm{~nm}$ and expressed as unit micro per milliliter $(\mathrm{U} / \mathrm{mL})$.

$$
\begin{gathered}
\text { Serum SOD inhibition ratio } \%= \\
=\frac{\left(\mathrm{OD}_{\text {control }}-\mathrm{OD}_{\text {control blank }}\right)-\left(\mathrm{OD}_{\text {sample }}-\mathrm{OD}_{\text {sample blank }}\right)}{\mathrm{OD}_{\text {control }}-\mathrm{OD}_{\text {control blank }}} \times 100 \%
\end{gathered}
$$

Serum SOD activity $(\mathrm{U} / \mathrm{mL})=$

$=\frac{\text { Serum SOD inhibition ratio }}{50 \%} \times \frac{\text { reaction system } 0.24}{\text { dilution multiple } 0.02}$

Determination of reduced GSH activity. GSH detection assay kit (cat no. A006-2) from Nanjing Jiancheng Bioengineering Institute (Nanjing, People's Republic of China) was used to test reduced GSH activity following the manufacturer's instructions. In this reaction, GSH reacts with dithiodinitrobenzoic acid (DTNB) to form a yellow compound. Glutathione stabilizes enzymes containing a thiol group and prevents oxidative damage to hemoglobin and other cofactors. GSH is a low molecular scavenger that can scavenge $\mathrm{O}_{2}$ and $\mathrm{H}_{2}$. The content of reduced glutathione was determined quantitatively by colorimetry at $405 \mathrm{~nm}$ wavelengths. Using a standard OD curve, the reduced GSH activity was expressed as milligram per liter (mg/L).

Serum GSH activity $(\mathrm{mg} / \mathrm{L})=\frac{\mathrm{OD}_{\text {sample }}-\mathrm{OD}_{\text {blank }}}{\mathrm{OD}_{\text {standard blank }}-\mathrm{OD}_{\text {blank }}} \times 20$

Determination of CAT activity. CAT detection assay kit (cat no. A007-1 Visible light method) from Nanjing Jiancheng Bioengineering Institute (Nanjing, People's Republic of China) was used to evaluate CAT activity following the manufacturer's instructions. The kit detects CAT's ability to decompose $\mathrm{H}_{2} \mathrm{O}_{2}$, which can be stopped quickly by adding ammonium molybdate. The remaining $\mathrm{H}_{2} \mathrm{O}_{2}$ can be used as ammonium aluminate. CAT activity was calculated by measuring the change of the pale yellow complex at $405 \mathrm{~nm}$ wavelengths. The amount of $\mathrm{H}_{2} \mathrm{O}_{2}$ decomposed by 10 per milliliter of serum or plasma per second was set as the unit of activity. Using a standard OD curve, the CAT activity was expressed as micro per milliliter $(\mathrm{U} / \mathrm{mL})$.

$$
\begin{gathered}
\text { Serum CAT activity }(\mathrm{U} / \mathrm{mL})= \\
=\left(\mathrm{OD}_{\text {control }}-\mathrm{OD}_{\text {sample }}\right) \times 271 * \times 1 / 60
\end{gathered}
$$

where: $271 *=$ reciprocal of the slope.

Determination of MDA activity. MDA detection assay kit (cat no. A003-1 TBA) from Nanjing Jiancheng Bioengineering Institute (Nanjing, People's Republic of China) was used to evaluate MDA activity following the manufacturer's instructions. The reaction of fatty acids with free radicals results in malondialdehyde, which is the final product of lipid peroxidation. The level of malondialdehyde can be evaluated with thiobarbituric acid, which can be measured colorimetrically. Using the blood serum sample, $200 \mathrm{ml}$ was mixed with $800 \mathrm{ml}$ phosphate buffer, $25 \mathrm{ml}$ BHT solution, and $500 \mathrm{ml}$ of $30 \%$ TCA. The tubes were boiled $90^{\circ} \mathrm{C}$ for 40 min. The tubes were agitated using a vortex and incubated on ice for $2 \mathrm{~h}$ for cooling. Next, the tubes were centrifuged at $3500 \mathrm{rpm}$ for $10 \mathrm{~min}$, and $1 \mathrm{ml}$ supernatant was collected. The supernatant was mixed with $250 \mathrm{ml}$ of TBA and $75 \mathrm{ml}$ of EDTA, mixed using a vortex, and placed in a hot water bath for $15 \mathrm{~min}$. Samples were moved to room temperature and absorbance was read in $\mathrm{UV} / \mathrm{V}$ as spectrophotometer F4500 (Hitachi, Japan) at $532 \mathrm{~nm}$. Using a standard OD curve, MDA activity was expressed as nano-mole per milliliter $(\mathrm{nmol} / \mathrm{mL})$.

Serum MDA activity $(\mathrm{nmol} / \mathrm{mL})=\frac{\mathrm{OD}_{\text {sample }}-\mathrm{OD}_{\text {blank }}}{\mathrm{OD}_{\text {standard }}-\mathrm{OD}_{\text {blank }}} \times 10$

Statistical analysis. Data were analyzed by repeatedmeasures two way ANOVA and Bonferroni's multiple comparisons test with a significance level of 5\% using Graph pad Prism (Version 7.04, Graph Pad Software Inc., San Diego, CA). All data are presented as means \pm standard error. Comparisons were considered to be statistically significant when $\mathrm{p} \leq 0.05$.

\section{Results and discussion}

Clinical signs. All the OF-treated heifers showed clinical signs of distinct acute ruminal and systemic acidosis symptoms, including increased heart rate, anorexia, depression, in-appetence, watery diarrhea, and transient fever. Control heifers showed no signs of systemic disease. During locomotion assessment, the clinical signs of laminitis were initially observed at $24 \mathrm{~h}$ after OF overload and found continuous increase up to $48 \mathrm{~h}$ at which we found locomotion score 2-3. The maximum locomotion score 3-5 was observed from $60 \mathrm{~h}$ which confirmed the acute laminitis in Chinese dairy heifers. These locomotion score were constant between $60 \mathrm{~h}$ to $72 \mathrm{~h}$ and we did not find any significant change. Therefore, the animals were then euthanized for further experimental requirements. These results are in line with (6) who found acute laminitis at 60$-120 \mathrm{~h}$ of OF induction, while in our study the laminitis was observed maximum at $48 \mathrm{~h}$. These early signs of acute laminitis can be correlated with animal breed, physical health, environmental condition and dose 


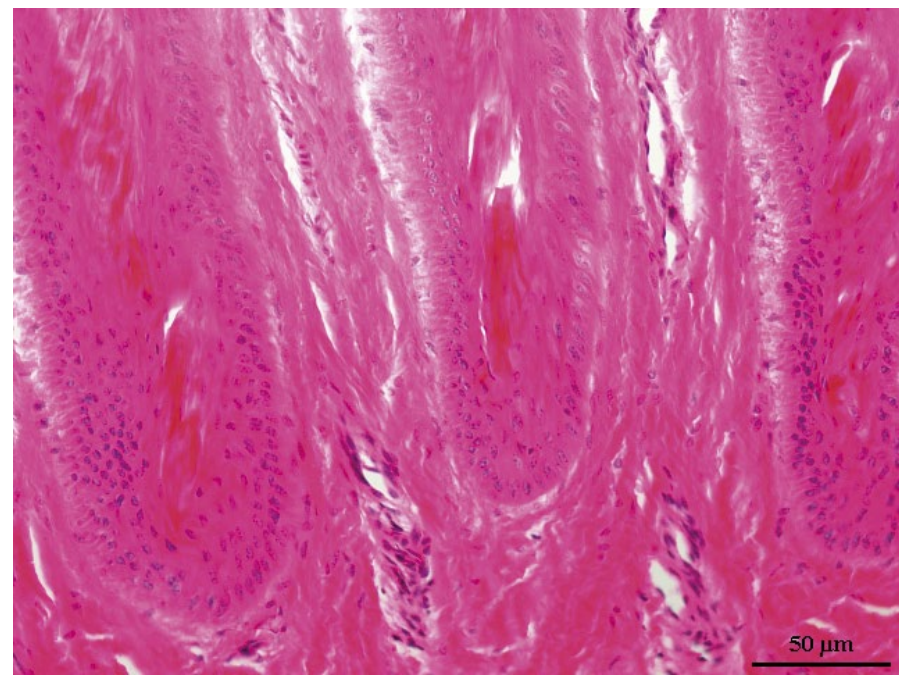

Fig. 1. Right hand lateral claw of control heifer

Explanations: Transverse section of tissue from the dorso-abaxial claw wall, Scale bar is $50 \mu \mathrm{m}$. Sections of innermost tips of the lamellar layer stained with hematoxylin and eosin. Control heifer, right hand lateral claw. Well defined basement membrane, columnar basal cells with dark-stained nuclei (heterochromatin)

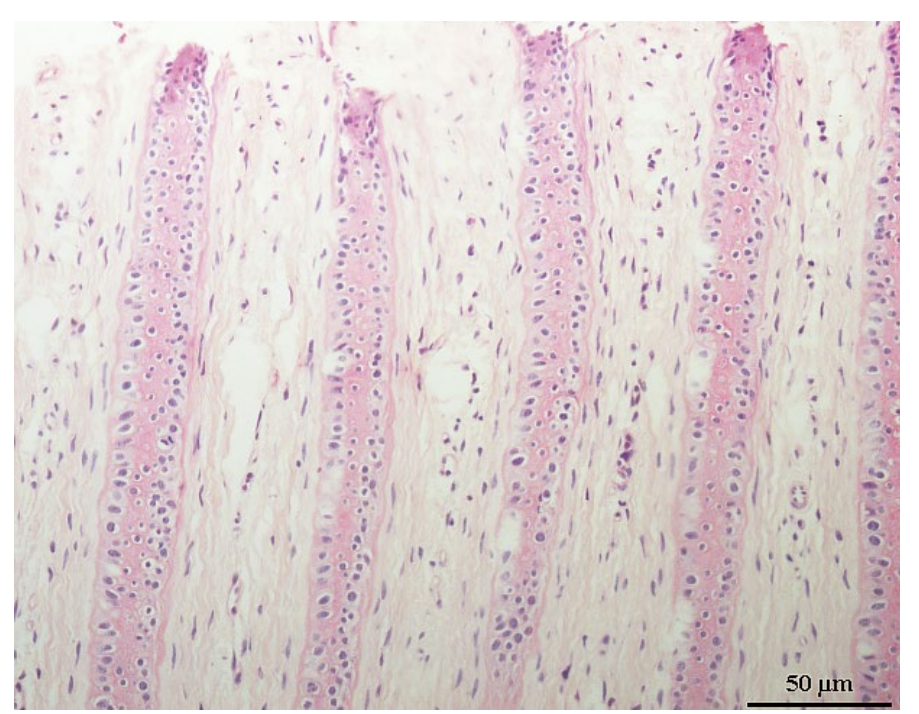

Fig. 2. Right hand lateral claw of OF treated heifer

Explanations: Transverse section of tissue from the dorso-abaxial claw wall, Scale bar is $50 \mu \mathrm{m}$. Sections of innermost tips of the lamellar layer stained with periodic acid-Schiff. Heifer euthanized after $72 \mathrm{~h}$ of OF overload, right hand lateral claw. Stretched lamellae, cell layer thick, little blurry and wavy basement membrane, cuboidal basal cells with rounded, light stained nuclei. Insertion shows detached basement membrane at the tip of the upper lamellae

of oligofructose overload. Control heifers showed no change in locomotion score during the experiments. Histopathological examination of claw biopsy was carried out and preliminary results are presented in Fig. 1 and 2. In summary, clear differences were observed between the lamellar regions of OF treated and control heifers. These results are in line with (7) who confirmed the acute laminitis in heifers after OF overload by histopathological examination.

Superoxide dismutase (SOD). Serum SOD activity of the control and OF-treated heifers with acute laminitis are listed in Fig. 3. We found a significant reduction in SOD activity in OF-treated dairy heifers compared to the control group $(\mathrm{p}<0.01)$. SOD level was significantly lower $(\mathrm{p}<0.05)$ at $18 \mathrm{~h}$ compared to the control group, and there was a significant reduction in SOD levels $(\mathrm{p}<0.01)$ from $24 \mathrm{~h}$ to $72 \mathrm{~h}$ in OF-treated heifers. These results highlight that oxidative stress is involved in the pathogenesis of acute laminitis in dairy heifers.

Reduced glutathione (GSH) activity. A serum GSH levels of the control and OF-treated heifers are listed in Fig. 4. GSH level were similar for the OF-treated and control heifers $(\mathrm{p}>0.05)$.

Catalase (CAT). Serum CAT levels of the control and OF-treated heifers are listed in Fig. 5. CAT levels

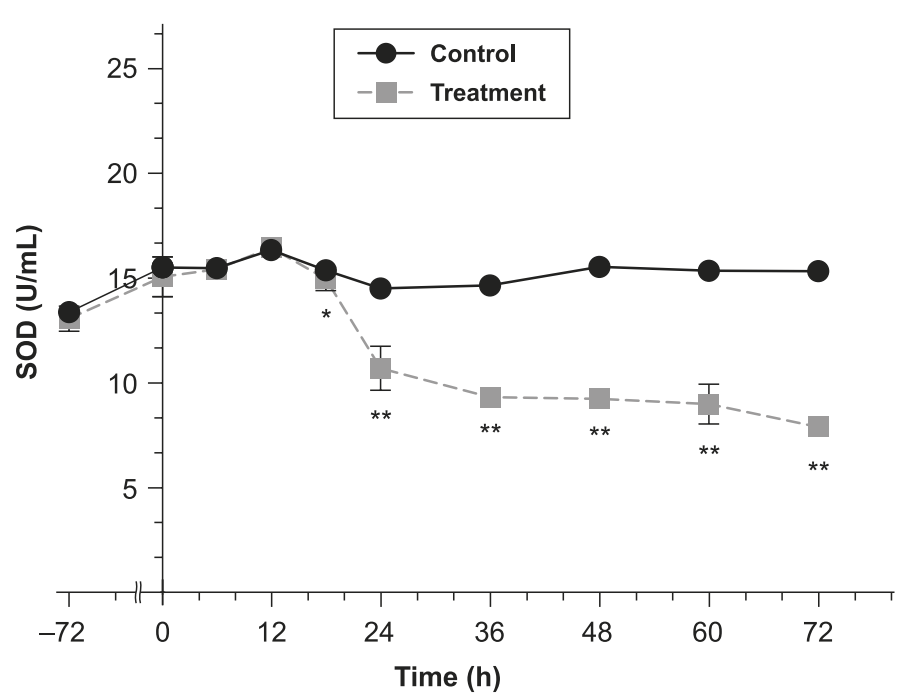

Fig. 3. Concentration $(\mathrm{U} / \mathrm{mL})$ Change of SOD from (-72) to $72 \mathrm{~h}$

Explanations: *indicated the differences were significantly $(\mathrm{p}<0.05)$ compared OF-treated group with the control group; $* *$ indicated the differences were significantly $(\mathrm{p}<0.01)$ compared OF-treated group with the control group

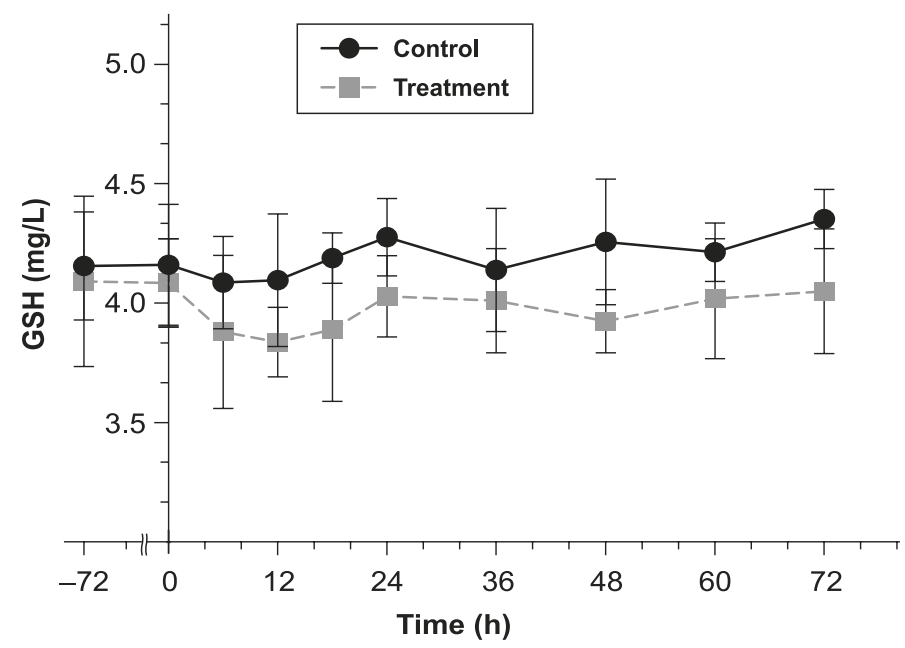

Fig. 4. Concentration (mg/L) Change of GSH from (-72) to $72 \mathrm{~h}$

Explanations: Concentration change of GSH from $(-72)$ to $72 \mathrm{~h}$ indicated the differences non-significantly $(p>0.05)$ compared OF-treated group with the control group 


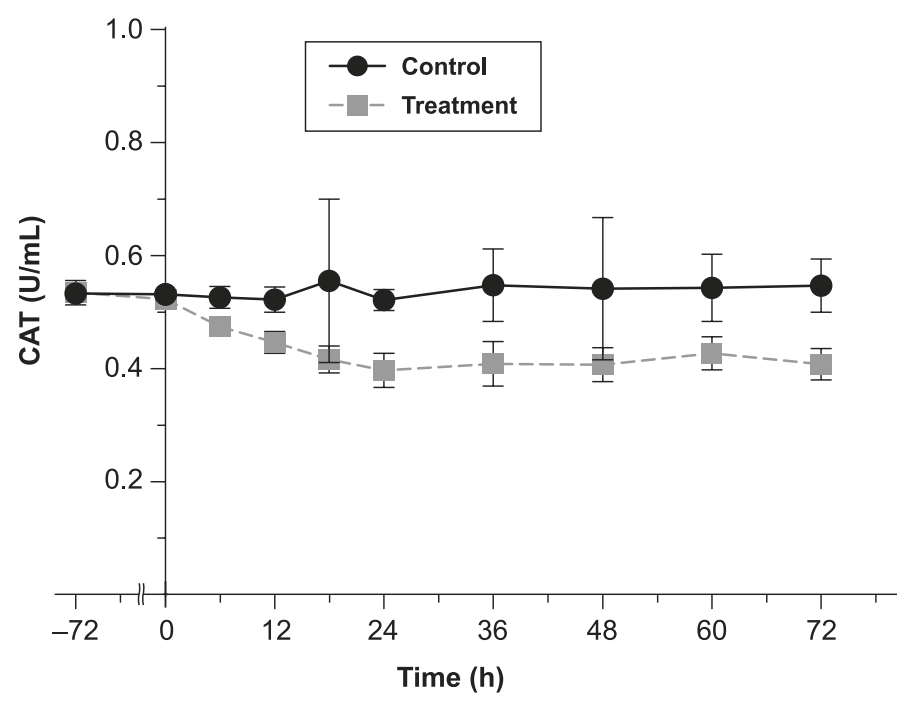

Fig. 5. Concentration $(\mathrm{U} / \mathrm{mL})$ Change of CAT from (-72) to $72 \mathrm{~h}$

Explanations: Concentration change of CAT from $(-72)$ to $72 \mathrm{~h}$ indicated the differences non-significantly $(p>0.05)$ compared OF-treated group with the control group

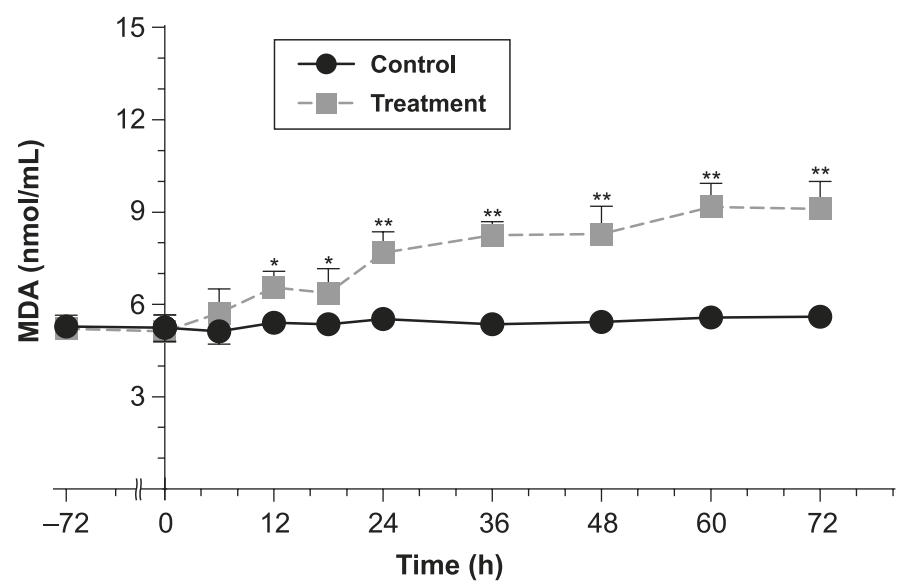

Fig. 6. Concentration (nmol/mL) Change of MDA from (-72) to $72 \mathrm{~h}$

Explanations: *indicated the differences were significantly $(p<0.05)$ compared OF-treated group with the control group; $* *$ indicated the differences were significantly $(\mathrm{p}<0.01)$ compared OF-treated group with the control group

were similar in OF-treated and control dairy heifers $(\mathrm{p}>0.05)$.

Lipid peroxidation. A serum MDA activity of the control and OF-treated heifers with acute laminitis are listed in Fig. 6. MDA is a marker of oxidative stress, and we found significantly higher MDA levels $(p<0.01)$ in OF-treated heifers compared with the control group. The mean MDA levels were significantly higher $(\mathrm{p}<0.05)$ at $12 \mathrm{~h}-18 \mathrm{~h}$ compared to the control group, and significantly higher $(\mathrm{p}<0.01)$ from $24 \mathrm{~h}$ to $72 \mathrm{~h}$ in OF-treated heifers. Therefore oxidative stress is likely involved in the etiopathogenesis of acute laminitis, and deficient levels of antioxidants (enzymatic and nonenzymatic) may be correlated to oxidative stress status in ill heifers. When MDA enzyme activity was examined, the relationship between OF-treated group and control groups were statistically significant $(\mathrm{p}<0.05)$.
The increased production of excessive free radicals caused by the animal's interaction with various stressinducing factors and the failure of the antioxidant defense system to remove these free radicals leads to oxidative stress $(4,47)$. Oxidative stress plays an important role in the pathogenesis of various diseases, such as respiratory, joint and foot diseases, sepsis, mastitis, acidosis, ketosis, enteritis and endoparasitic diseases in livestock $(5,24,37)$.

A previous study (16) described a number of protection mechanisms against ROS in animals. Antioxidant enzymes include SOD, which catalyzes the breakdown of superoxide radicals to water and hydrogen peroxide, and CAT, which catalyzes the dismutation of hydrogen peroxide to water and oxygen. An important co-factor and antioxidant for various antioxidant enzymes is GSH, which is a tri-peptide thiol (20). We found significant changes in SOD levels, but not in CAT activity in heifers with laminitis. This may be because SOD is the central defense mechanism against ROS, and is involved in detoxification of superoxide radicals (12). The hydrogen peroxide that is generated from the reaction that SOD catalyses is then converted to water by CAT. It may be that the oxidative effects of laminitis are not extensive enough to affect CAT. SOD levels decrease in heifers with lameness (49), and in dairy heifers that have foot-and-mouth disease $(19,26)$.

An indicator of oxidative stress in cells is lipid peroxidation. Polyunsaturated fatty acids produce lipid peroxides that are unstable that are then disintegrated to MDA. The quantification of MDA is a proxy for lipid peroxidation (35). MDA is one of the main biochemical markers used to determine the degree of cellular damage in tissues $(29,33)$. MDA levels were significantly higher $(\mathrm{p}<0.01)$ in heifers with lameness (49). Previous studies have found that MDA increases calves with inflammatory diseases, such as arthritis and omphalitis $(2,46)$, in the dairy cows with footand-mouth disease $(19,26)$ dogs with renal diseases (18) and sheep infected with Dicrocoelium dendriticum (35). Superoxide radical and hydrogen peroxide also accumulate as a result of brain injury (21).

In the present study, MDA levels were significantly higher in OF-treated heifers, highlighting that laminitis increases the presence of lipid peroxidation products. Polyunsaturated fatty acids are the principal targets of oxygen radicals, and disruption of fatty acids can lead to disorganization of cell structure (31).

The increased serum MDA level in lame heifers further verified that acute laminitis in dairy heifers caused oxidative stress. Significantly decreased levels of SOD observed in heifers with laminitis also provide support that oxidative impairment is a likely part of the pathogenesis of acute laminitis in heifers.

CAT and GSH are important antioxidants that inhibit free radicals (27), catalyzing reactions that reduce lipid peroxides and hydrogen in cells (48). GSH is a nonenzymatic antioxidant that defends the body against 
oxidative stress, and is involved in inactivation of free radicals (25).

CAT levels showed a non-significant decrease $(p>0.05)$ in OF-treated heifers compared to the control group. This nonsignificant decrease in the serum CAT levels may be interpreted as the excessive usage of CAT activity as a result of hoof leaf inflammation. A previous study also found non-significant differences in CAT activity in heifers with lameness (49).

Moreover, we found that serum GSH levels showed a non-significant decrease $(\mathrm{p}>0.05)$ in the OF-treated group compared to the control group. This is consistent with a previous study that showed that GSH activity does not change in heifers with lameness (49).

ROS include superoxide radicals, hydrogen peroxide and hydroxyl radical. ROS affect the normal function of biomolecules such as proteins, nucleic acids, and cell membrane phospholipids. Free radicals are produced through the stepwise reduction of molecular oxygen (36). Normal cellular function does produce free radicals; however, excessive production and insufficient elimination of free radicals can lead to irreversible damages to the cell (23).

In conclusion, we found a relationship between acute laminitis and oxidative stress and found that $\mathrm{SOD}, \mathrm{GSH}, \mathrm{CAT}$, and MDA levels may play a role in the etiopathogenesis of acute laminitis in dairy heifers. However, more research is needed to describe these responses and to develop strategies to control acute laminitis in heifers.

\section{References}

1. Anderson M. E.: Glutathione: an overview of biosynthesis and modulation. Chem. Biol. Interact. 1998, 111-112, 1-4.

2.Bozukluhan K., Merhan O., Öğ̈̈n M., Cihan M., Gökçe G.: Determination of the levels of some oxidative stress parameters in calves with omphalitis. F. Ü. Sağ. Bil. Vet. Derg. 2016, 30, 79-81

3. Celi P.: Oxidative stress in ruminants, [in:] Mandelker L., Vajdovich P. (eds.): Studies on Veterinary Medicine, Oxidative Stress in Applied Basic Research and Clinical Practice 5. Springer 2011, p. 191-231.

4. Celi P.: The role of oxidative stress in small ruminants' health and production. R. Bras. Zootec. 2010, 39, 348-363, doi: http://dx.doi.org/10.1590/ S1516-35982010001300038.

5. Celi P., Di Trana A., Claps S.: Effects of the plane of nutrition on oxidative stress in goats during the peripartum period. Vet. J. 2010, 184, 95-99, doi: 10.1016/j.tvj1.2009.01.014

6. Danscher A. M., Enemark J. M. D., Telezhenko E., Capion N., Ekstrøm C. T., Thøfner M. B.: Oligofructose overload induces lameness in cattle. J. Dairy Sci. 2009, 92, 607-616, doi: 10.3168/jds.2008-1271.

7.Danscher A. M., Tølbøll T. H., Wattle O.: Biomechanics and histology of bovine claw suspensory tissue in early acute laminitis. J. Dairy Sci. 2010, 93, 53-62, doi: 10.3168/jds.2009-2038.

8. Del Rio D., Stewart A. J., Pellegrini N.: A review of recent studies on malondialdehyde as toxic molecule and biological marker of oxidative stress. Nutr. Metab. Cardiovasc. Dis. 2005, 15, 316-328

9. Folnožić I., Turk R., Đuričić D., Vince S., Pleadin J., Flegar-Meštrić Z., Valpotić H., Dobranić T., Gračner D., Samardžija M.: Influence of body condition on serum metabolic indicators of lipid mobilization and oxidative stress in dairy cows during the transition period. Reprod. Domest. Anim. 2015, 50, 910-917, doi: 10.1111/rda.12608.

10. Gawel S., Wardas M., Niedworok E., Wardas P.: MDA as a lipid peroxidation marker. Wiad. Lek. 2004, 57, 453-455.

11. Gonzales R., Auclair C., Voisin E., Gautero H., Dhermy D., Boivin P.: Superoxide dismutase, catalase and glutathione peroxydase in red blood cells from patients with malignant diseases. Cancer Res. 1998, 44, 4137-4139.
12. Gonzales R., Auclair C., Voisin E., Gautero H., Dhermy D., Boivin P.: Superoxide dismutase, catalase, and glutathione peroxidase in red blood cells from patients with malignant diseases. Cancer Res.1984, 44, 4137-4139.

13. Hailemariam D., Mandal R., Saleem F., Dunn S. M., Wishart D. S., Ametaj $B$. $N$.: Identification of predictive biomarkers of disease state in transition dairy cows. J. Dairy Sci. 2014, 97, 2680-2693, doi: 10.3168/jds.2013-6803.

14. Halliwell B.: Antioxidant defence mechanism: from the beginning to the end (of the beginning). Free Rad. Res. 1999, 31, 261-272.

15. Halliwell B., Chirico S.: Lipid peroxidation: its mechanism, measurement, and significance. Am. J. Clin. Nutr. 1993, 57, 715-725.

16. Halliwell B., Gutteridge J. M. C.: Antioxidant defenses, [in:] Halliwell B. Gutteridge J. M. C. (eds.): Free Radicals in Biology and Medicine. Oxford Clarendon Press 1999, p. 200-216.

17. Heinecke L. F., Grzanna M. W., Au A. Y., Mochal C. A., Rashmir-Raven A., Frondoza C. G.: Inhibition of cyclooxygenase-2 expression and prostaglandin E2 production in chondrocytes by avocado soybean unsaponifiables and epigallocatechin gallate. Osteoarthritis Cartilage 2010, 18, 220-227, doi: 10.1016/ j.joca.2009.08.015.

18. Kargin F., Fidanci U. R.: Kidney diseases and antioxidative metabolism in dogs. Turk. J. Vet. Anim. Sci. 2001, 25, 607-613.

19. Khoshvaghti A., Askari A., Nazifi S., Ghane M.: Evaluation of some antioxidant enzymes in cattle infected with foot and mouth virus. İ. Ü. Vet. Fak. Derg. 2014, 40, 70-75.

20. Kidd P. M.: Glutathione: systemic protectant against oxidative and free radical damage. Alternative Med. Rev. 1997, 2, 155-176.

21. Kontos H. A., Wei E. P.: Superoxide production in experimental brain injury. J. Neurosurg. 1986, 64, 803-807, doi: 10.3171/jns.1986.64.5.0803.

22. Kumar A., Dwivedi H. P., Swarup D.: Oxidative Stress in Periparturient Metabolic Disorders, [in:] Production Diseases of Dairy Animals 2011, p. 19-27.

23. Lopaczynski W., Zeisel S. H.: Antioxidants, programmed cell death, and cancer. Nutr. Res. 2001, 21, 295-307, doi: https://doi.org/10.1016/S0271-5317 (00)00288-8

24. Lykkesfeldt J., Svendsen O.: Oxidants and antioxidants in disease: oxidative stress in farm animals. Vet. J. 2007, 173, 502-511, doi: 10.1016/j.tvj1.2006. 06.005 .

25. Mates $J$. M.: Effects of antioxidant enzymes in the molecular control of reactive oxygen species toxicology. Toxicol. 2000, 153, 83-104, doi: https://doi. org/10.1016/S0300-483X(00)00306-1.

26. Nath R., Prasad R. L., Sarma S.: Oxidative stress biomarkers in cross bred cows affected with foot and mouth disease. Ind. J. Anim. Res. 2014, 48, 628-632, doi: 10.5958/0976-0555.2014.00045.4.

27. Nimse S. B., Pal D.: Free radicals, natural antioxidants, and their reaction mechanisms. RSC Advances 2015, 5, 27986-28006, doi: 10.1039/C4RA13315C.

28. Osorio J. S., Fraser B. C., Graugnard D. E., Singh S. S., Drackley J. K., Garrett E. F., Loor J. J.: Corium tissue expression of genes associated with inflammation, oxidative stress, and keratin formation in relation to lameness in dairy cows. J. Dairy Sci. 2012, 95, 6388-6396, doi: 10.3168/jds.2011-5143.

29. Özcan O., Erdal H., Çakırca G., Yönden Z.: Oxidative stress and its impacts on intracellular lipids, proteins, and DNA. J. Clin. Exp. Invest. 2015, 6, 331-336, doi: https://doi.org/10.5799/ahinjs.01.2015.03.0545.

30. Palmieri B., Sblendorio V: Oxidative stress tests: overview on reability and use part I. Eur. Rev. Med. Pharmacol. Sci. 2007, 11, 309-342.

31. Patterson R. A., Leake D. S.: Human serum, cysteine, and histidine inhibit the oxidation of low-density lipoprotein less at acidic pH. FEBS Lett. 1998, 434, 317-21, doi: 10.1016/s0014-5793(98)01002-3.

32. Seyrek K., Yaylak E., Akşit H.: Serum Sialic Acid, Malondialdehyde, Retinol, Zinc, And Copper Concentrations. Bull. Vet. Inst. Pulawy 2008, 52, 281-284.

33. Sezer K., Keskin M.: Role of the free oxygen radicals on the pathogenesis of the diseases. Sağ. Bil.Vet. Derg. F. Ü. 2014, 28, 49-56.

34. Shan X. O., Aw T. Y., Jones D. P.: Glutathione dependent protection against oxidative injury. Pharmacol. Ther. 1990, 47, 61-71.

35. Simsek S., Yuce A., Utuk A. E.: Determination of serum malondialdehyde levels in sheep naturally infected with Dicrocoelium dendriticum. F.Ü. Sağ. Bil. Derg. 2006, 20, 217-220.

36. Singh R. P., Murthy K. N. C., Jayaprakasha G. K.: Studies on the antioxidant activity of pomegranate (Punica granatum) peel and seed extracts using in vitro models. J. Agr. Food chem. 2002, 50, 81-86, doi: 10.1021/jf010865b.

37. Talukder S., Gabai G., Celi P.: The use of digital infrared thermography and measurement of oxidative stress biomarkers as tools to diagnose foot lesions in sheep. Small Rum. Res. 2015, 127, 80-85, doi: https://doi.org/10.1016/ j.smallrumres.2015.04.006. 
38. Thoefner M. B., Pollitt C. C., Van Eps A. W., Milinovich G. J., Trott D. J., Wattle O., Andersen P. H.: Acute bovine laminitis: A new induction model using alimentary oligofructose overload. J. Dairy Sci. 2004, 87, 2932-2940, doi: 10.3168/jds.S0022-0302 (04)73424-4.

39. Thomsen P. T., Munksgaard L., Tøgersen F. A.: Evaluation of a lameness scoring system for dairy cows. J. Dairy Sci. 2008, 91, 119-126, doi: 10.3168/ jds.2007-0496.

40. Tomlinson D. J., Mülling C. H., Fakler T. M.: Invited review: formation of keratins in the bovine claw: roles of hormones, minerals, and vitamins in functional claw integrity. J. Dairy Sci. 2004, 87, 797-809, doi: 10.3168/jds. S0022-0302 (04)73223-3.

41. Turk R., Folnožić I., Đuričić D., Vince S., Flegar-Meštrić Z., Dobranić T., Valpotić H., Samardžija M.: Relationship between paraoxonase-1 activity and lipid mobilisation in transition dairy cows. Vet. Archiv 2016, 86, 601-612.

42. Turk R., Podpečan O., Mrkun J., Kosec M., Flegar-Meštrić Z., Perkov S. Starič J., Robić M., Belić M., Zrimšek P.: Lipid mobilization and oxidative stress as metabolic adaptation processes in dairy heifers during the transition period. Anim. Reprod. Sci. 2013, 141, 109-115, doi: https://doi.org/10.1016/ j.anireprosci.2013.07.014.

43. Verhagen H., Buijsse B., Jansen E., Bueno-de-Mesquita B.: The state of antioxidant affairs. Nutri. Today 2006, 41, 244-250.
44. Winrow V. R., Winyard P. G., Morris C. J., Blake D. R.: Free radicals in inflammation: second messengers and mediators of tissue destruction. Br. Med. Bull. 1993, 49, 506-522.

45. Young I. S., Woodside J. V.: Antioxidants in health and disease. J. Clin. Pathol. 2001, 54, 176-186, doi: 10.1136/jcp.54.3.176.

46. Yurdakul G., Saritas Z. K.: Evaluation of clinic, radiographic and some biochemical blood serum and synovial fluid parameters of arthritis cases in calves. Kocatepe Vet. J. 2013, 6, 13-22, doi: https://doi.org/10.22319/rmcp. v10i1.4727.

47. Yurdakul I., Yildirim B. A.: Assessment of Oxidative Status in Foot Diseases of Sheep. Acta Sci. Vet. 2018, 46, 1-6, doi: 10.22456/1679-9216.89196.

48. Zengin K., Mert H., Mert N.: Catalase activity and the levels of MDA, AOPP in sheeps with subclinical mastitis. Res. Agri. Vet. Sci. 2017, 1, 5-11.

49. Zhao X. J., Wang X. Y., Wang J. H., Wang Z. Y., Wang L., Wang Z. H.: Oxidative stress and imbalance of mineral metabolism contribute to lameness in dairy cows. Biol. Trac. Elem. Res. 2015, 164, 43-49, doi: 10.1007/s12011-0140207-1.

Corresponding author: Prof. Dr. Hong Bin Wang, Ph. D., Department of Veterinary Surgery, College of Veterinary Medicine, Northeast Agricultural University, Harbin 150030, P. R. China; e-mail: hbwang1940@163.com 